\title{
USING STRUCTURATION THEORY IN ACTION RESEARCH: AN INTRANET DEVELOPMENT PROJECT
}

\author{
Jeremy Rose \\ Department of Computing Science \\ University of Aalborg \\ Frederik Bajers Vej 7 \\ DK-9220 Aalborg \\ Denmark \\ Paul Lewis \\ Department of Management Science \\ The Management School \\ Lancaster University \\ Bailrigg \\ Lancaster LA1 4YX \\ United Kingdom
}

\begin{abstract}
Structuration theory, Giddens' meta theory of social practice, has been used for theorizing the IS field and for analyzing empirical case studies, but has been little used in any practical or action research context. In the action research project reported here, which concerns the development of an intranet in a university department, structurational analysis was woven into the action research framework. This enabled social insight and reflections, which would not have been the primary focus of an analyst using a conventional systems development methodology, and facilitated the shaping offuture developments for the intranet. Many of these developments have been implemented and proved successful.
\end{abstract}

\section{INTRODUCTION}

Social theory has a substantial part to play in the development of the discipline of IS and in helping to understand and interact with the societal, 
organizational and personal contexts without which information technology is meaningless. Anthony Giddens has made a substantial contribution to that theory, and his mature formulation of structuration theory (expressed in The Constitution of Society 1984) has been used in the study of IS for some time. IS researchers have generated a significant body of structurational work (Barley 1986, 1990; Brooks 1997; DeSanctis and Poole 1994; Jones and Nandhakumar 1993; Karsten 1995; Nagasandrum and Bostrom 1994; Orlikowski 1992; Orlikowski and Robey 1991; Walsham 1993; Yates and Orlikowski 1992), and there are already three published reviews of this literature (Jones 1997; Rose 1998; Walsham and Han 1991). In the most recent of these, Rose (1998) points out that ST has been used to theorize the field of IS and to analyze empirical situations involving IS, but little attempt has been made to "operationalize" the theory - that is, to use structuration theory in an attempt to directly influence IS practice.

The purpose of this paper, then, is to show structuration theory in action as an integral part of an information systems development action research project. Information system development is assumed to have rather a wide meaning for this context, taking in both changes to work practices and social structures around information and communication technologies. Structuration theory is already quite widely understood within the WG 8.2 community and is not further elaborated here. The research work was complex, and involved extensive use and development of soft systems methodology and many technical elements that are always part of development work, but these are not much described here either. They may be found in Rose (2000).

\section{ACTION RESEARCH IN IS}

Hult and Lenning (1980) suggest that:

Action research simultaneously assists in practical problem solving and expands scientific knowledge, as well as enhances the competencies of the respective actors, being performed collaboratively in an immediate situation using data feedback in a cyclical process aiming at an increased understanding of a given social situation, primarily applicable for the understanding of change processes in social systems and undertaken within a mutually acceptable ethical framework.

Baskerville and Wood-Harper (1998) widen this definition by suggesting that action research is characterized by:

- multivariate social settings

- interpretive assumptions about observation 
- intervention by the researcher

- participatory observation

- the study of change in the social setting

They distinguish between iterative process models (typically where action and problem diagnosis activities alternate until sufficient improvement is obtained) and linear process models (where a set of steps such as analysis, fact-finding, conceptualization, planning, implementation, and evaluation are followed). They further distinguish between collaborative, facilitative, and expert styles of researcher involvement. Action research may have a fluid or rigorous structure. Research goals may vary between organizational development goals, systems design goals, and individual learning goals or theory development goals. None of these goals are mutually exclusive.

Checkland (1991) stresses the importance of defining the intellectual framework and methodology in advance of the research. This allows conceptual separation between theory, which is embodied in the methodology, and practice, enabling the reflection and comparison which leads to learning about both. In this type of research, Checkland distinguishes between the intellectual framework of ideas, the methodology that embodies them, and the research situation, or area of application (Figure 1)

Valid forms of action research in IS, according to Baskerville and WoodHarper, include

- canonical action research (Baskerville 1993)

- prototyping (Kyng 1991)

- soft systems (Checkland and Holwell 1998)

- action science (Reponen 1992)

- participant observation (Jepsen et al. 1989)

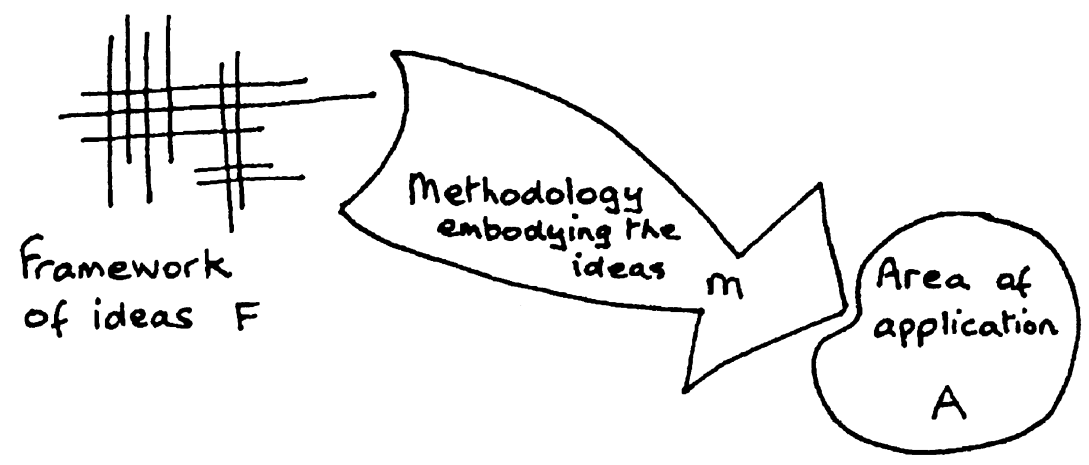

Figure 1. A Basic Conceptualization of Intellectual Work (Checkland and Scholes 1990) 
- action learning (Naur 1983)

- multiview (Avison and Wood-Harper 1990)

- ETHICS (Mumford 1983)

- clinical field work (Hammer and Champey 1993)

- process consultation (Coad and Yourdon 1990)

The references are to published examples from the IS domain.

Acknowledged problems with action research include:

- goal dilemmas between the practical problems at hand and the research endeavor (Rapoport 1970);

- value dilemmas between roles as consultant and researcher, such as clients' belief in quick actions (quick wins) versus researchers' belief in careful abstract reflection before action (Rapoport 1970);

- difficulties establishing rigor and objectivity according to conventional positivist natural science traditions (Susman and Evered 1978);

- preoccupation with organizational problem solving at the expense of transferable theoretical understandings (Susman and Evered 1978);

- lack of epistemological clarity in theory testing and development (Rose 1997).

In this research work, the research method conforms to the descriptions given by Hult and Lenning and by Baskerville and Wood-Harper. A linear process model is adopted and the researcher involvement was collaborative. The framework of ideas underlying the work is structuration theory. The work has most in common with the SSM strand of IS action research, although this may not be evident from this account, which is focused elsewhere. Acknowledged problems of action research are tackled with a high degree of reflexive thinking and careful reporting. The research proceeded (over a period of about nine months) through formal interviews, workshops, and formal and informal meetings. Student feedback was collected through the mechanism of an assignment in which they were asked to evaluate the intranet, but there were also many informal contacts. Note-taking was principally via the diary method, and a large e-mail correspondence was collected.

\section{ADAPTING STRUCTURATION THEORY FOR ACTION RESEARCH IN ISD}

The next part of this paper sets out the path for operationalizing ST in the context of IS development. Part of this strategy involves translating the research style of the social theorist, concerned with pure theory and presented in the elaborate prose which is rich in associations for other social theorists, into discourse styles more familiar to practitioners (Figure 2). 


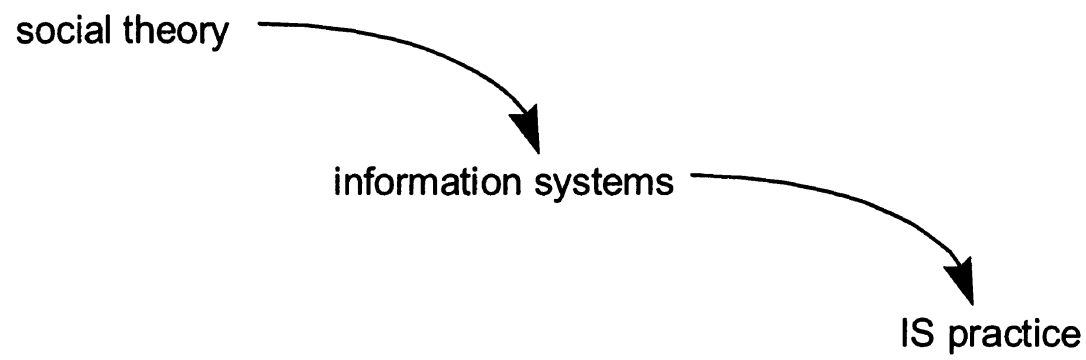

Figure 2. Translation between Discourse Styles

Translation represents one of the solutions to the problem of accessibility. Giddens' prose is dense and the concepts difficult to understand for those unfamiliar to the traditions of social theory. This theoretical language is far distant from the language of IS practitioners, whether they be managers or technical staff, even where the concepts represent familiar ideas, for instance in the realms of social action and consciousness. All translation involves loss of richness and faithfulness; however, this is sometimes a necessary price to pay in order to achieve accessibility.

In the present case, where the research starts with a known body of theory and the application area is also known, the research activities can be mapped out in more detail (Figure 3).

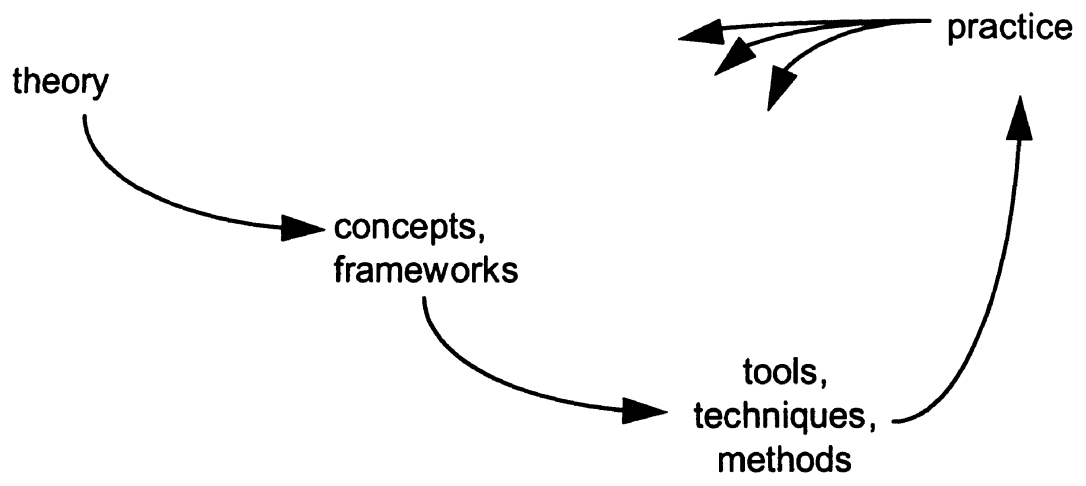

Figure 3. From Structuration Theory to ISD Practice 


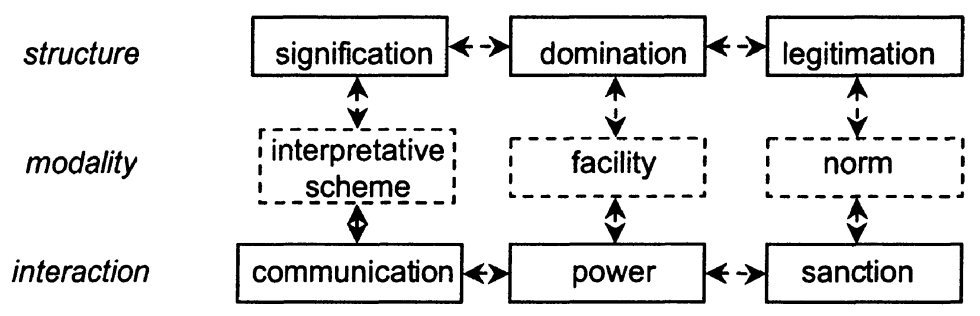

Figure 4. Dimensions of the Duality of Structure (Giddens 1984)

Structuration theory is too complex and diverse to be adapted wholesale. Relevant concepts must be selected and adapted into theoretical frameworks that have value for the IS community. Since the mode of practice of ISD is thought to be (at least partly) based on tools, techniques, and methods, a sensible course of action is to develop and refine ST-based tools in the action research cycle. Practitioners using such tools may be entirely unaware of the theory base behind their analysis. Tools, techniques, frameworks, method, and methodology represent the familiar aids to IS development practice.

Two frameworks based on structuration theory are shown here. They are designed to be used as analysis tools in action research situations. Development of the frameworks takes into account the need to represent situations in terms familiar to practitioners and to explicitly consider IS as an integral part of social practice. The frameworks focus on two aspects of social practice: regularity and change. The first supports the analysis of regularities of social practice, here characterized as interaction. It is based on Giddens' dimensions of the duality of structure model (Figure 4).

The principles of structure and agency and the three vertical axes are retained, but the language is altered to be more accessible. The word "structure" has inescapable connotations of organizational hierarchy in the English language and is regretfully abandoned. The modalities are dispensed with in favor of explicit analysis of the role of IT in each vertical axis. The theoretical basis for this analysis is given by Rose $(1999,2000)$. The interaction analysis framework is given in Figure 5.

\begin{tabular}{|l|l|l|l|}
\cline { 2 - 4 } context & meaning & power structure & norms \\
\cline { 2 - 4 } & & & \\
(IT role) & & & \\
\cline { 2 - 4 } & & & \\
\cline { 2 - 4 } & communication & use of power & sanctions \\
\cline { 2 - 4 } & &
\end{tabular}

Figure 5. Interaction Analysis Tool Based on Structuration Theory 
The second analysis framework supports the analysis of social change (here characterized as transformation) and is based on the "dimensions of social change" model (Figure 6). Again the language is changed to make it more accessible, although the basic concepts are retained. The role of IT in social change is explicitly considered. The transformation analysis tool is given in Figure 7.

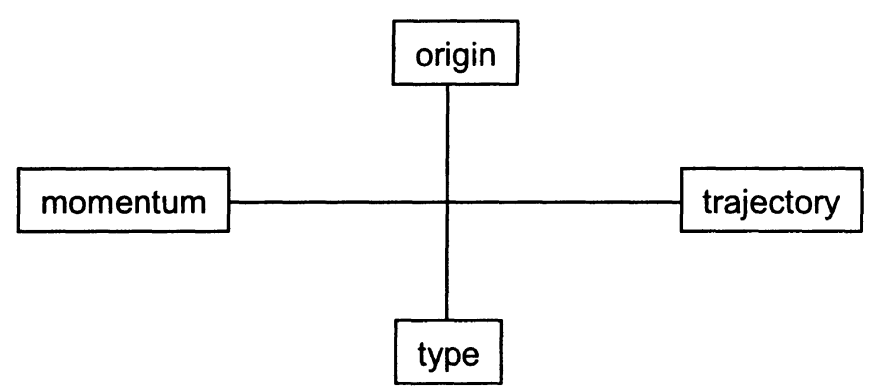

Figure 6. Dimensions of Social Change (Giddens 1984)

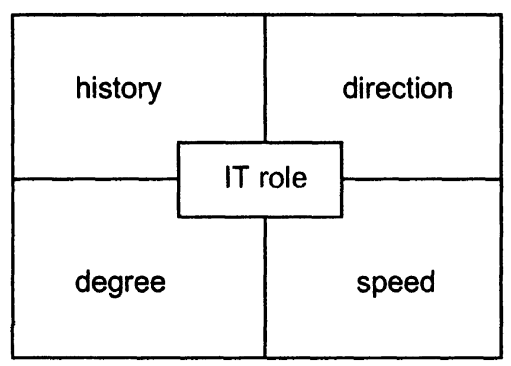

Figure 7. Transformation Analysis Tool Based on Structuration Theory

These frameworks, based on structuration, offer reasonably practical and approachable vehicles for the analysis of social regularity and social change, which can be used in a practical context. The use of these frameworks is shown in the following sections. 


\section{THE DEPARTMENTAL INTRANET PROJECT}

The intervention concerns the continuing development of an intranet in a technology department in a large university. Individual members of the department began experimenting with web technology several years ago. By and large they provided front-end pages that linked to course materials already available to students on the network. By 1997, there was an informal intranet, which two members of staff had built and to which others had contributed. After a visit to America, where the head of department (DD) was able to inspect the Massachusetts Institute of Technology (MIT) web sites, the decision was taken to formally develop an intranet that would support the work of the department. There was a period of consultation with departmental staff, but the decision was essentially a top-down one, taken on the basis that the department must have this facility to remain credible. Elements of the intranet's form and structure were discussed, a member of the university's IS unit (MF) co-opted to provide technical support, and the system went live in time for the new academic year in 1998. The initial concept for the system was to collect and make available to students the wide range of existing course-related material (e.g., teaching and lecture notes). It also included links to related business web sites, course and examination timetables, student handbooks, university regulations, module schedules, module materials including lecture slides, reading lists, links to other useful web sites, past examination papers, links to library catalogues, e-mail and feedback facilities, newsgroups, online notice boards, a search engine, and bulletin boards. The structure of pages largely reflected the structure of the department's teaching. Pages were organized hierarchically by course, year, and unit.

The web administrator (MF) provided the structure and top-level pages. He also provided templates and the navigation structure (the subject of some disagreement) for the course and unit pages. Academic staff members provided the material for the course and unit pages, mainly using simple web development tools such as Netscape Composer. A small minority of staff were familiar with HTML and Java and built more complex sites. A typical unit home page is shown in Figure 8.

When the action research intervention started in July 1999, the intranet had been in use for a whole teaching year. In many ways, the intranet's first year was reasonably successful, with staff members contributing much useful material, and most students using it, albeit in a limited and not necessarily very regular way. However, there were also problems. Populating the intranet pages with content was largely dependent on the academic staff (roughly 25), who had widely differing levels of interest and technical skills. Some were rather interested and happy to contribute. Others simply regarded it as an extra burden in their already complicated lives. Deadlines came and went, and many of the less crucial pages (for example, staff home pages) that had been set up as blank templates remained blank. Pages that had content displayed a wide variety of 


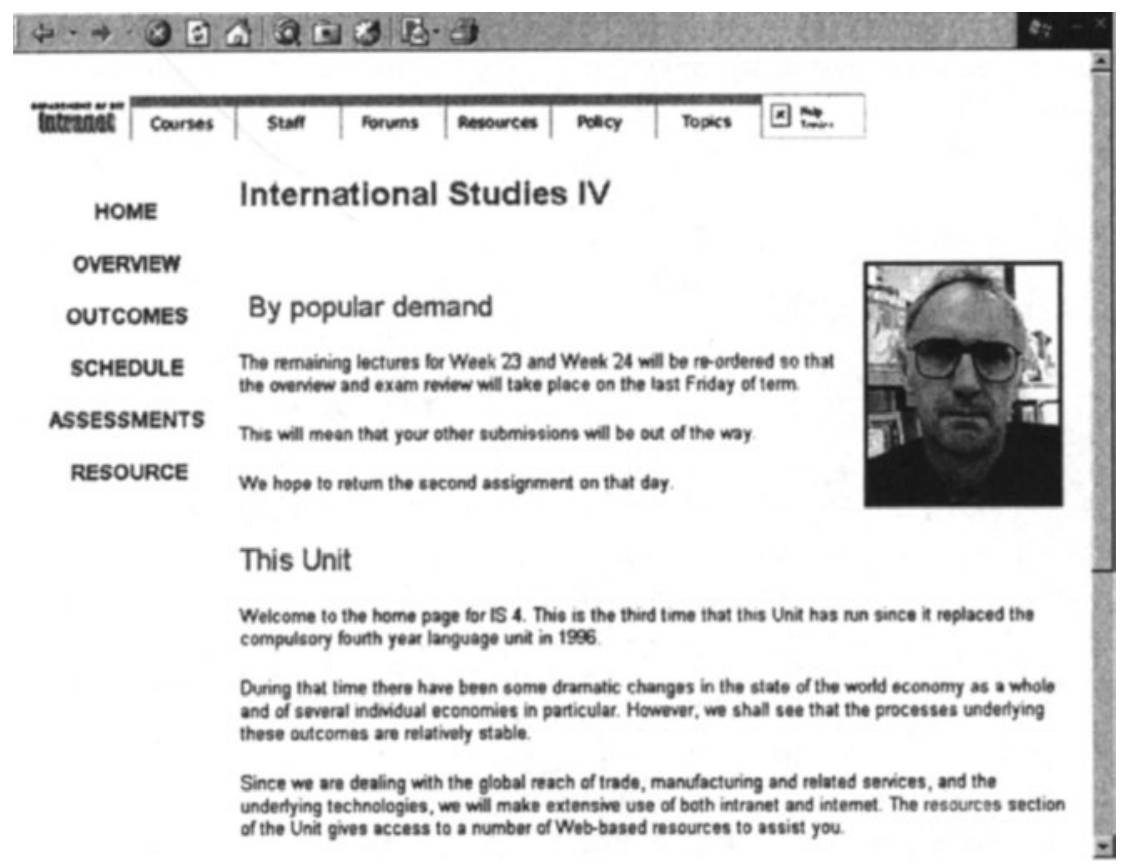

Figure 8. Unit Home Page

style and quality. Further problems arose as it became obvious that populating the pages was not a once and for all activity, but that the pages had to be updated regularly if they were to be relevant, and could also become seriously misleading if content was left past its sell-by date (for instance, at the beginning of an academic year there are 30 or so old unit schedules which are just wrong). Some problems with file transfer protocols and the simple development tool (Netscape Composer) that the staff were using led to the unwitting introduction of hundreds of bad links, which had to be laboriously traced and remedied. Many staff complained about the extra workload, and were skeptical about the rather unspecific benefits which were supposedly to accrue in the future. The students were less than enthusiastic. In many case they voted with their feet, and simply didn't use features that they didn't perceive as relevant, such as notice boards (which had nothing on them since the staff didn't use them either) and discussion forums. The automated feedback form remained entirely unused, with the students claiming it didn't work and the web administrator (MF) perfectly certain that it did. One of the intranet's original technology champions (GM) circulated an e-mail suggesting that the intranet should be abandoned entirely on the grounds that it was reducing social interactions with students. 
It was, therefore, difficult to claim that the intranet was an unqualified success and reasonable to undertake some work that would contribute to it's further development.

\section{THE INTERVENTION}

\subsection{Intervention Design}

The intervention took the following two-stage shape (Table 1):

(1) The analysis stage concentrated on making sense of the present situation. Research techniques included interviewing, document study (particularly a set of 44 final year student assessments of the intranet), and workshops. All interactions were recorded using the diary technique. An extensive e-mail debate was recorded. Analysis techniques included interaction models, rich pictures and structurational analysis. It culminated in a formal written document ("The Departmental Intranet - One Year On"), which was discussed, revised, and circulated.

(2) The design phase concentrated on conceptualising an improved situation through scenario building, choice, and change planning. A version of root definitions known as system definitions (Mathiassen et al. 2000), together with various SSM and structuration theory tools, were used to help conceptualize new ways of working and intranet support and to plan needed actions.

Both stages were marked by extensive participation.

The project also involved analysis techniques that were based on SSM tools and technical analysis. All the intervention activities were also supported by soft systems modeling (Rose 2000). These were important to the project, but are omitted from this description because of the focus of the paper.

Table 1. Stages, Tools, and Outputs for the Intranet Project

\begin{tabular}{|l|l|l|}
\hline Stage & Action research output & Tools \\
\hline 1. Analysis & $\begin{array}{l}\text { Negotiated formal review of } \\
\text { the current situation }\end{array}$ & $\begin{array}{l}\text { structurational analysis (interactions), } \\
\text { SSM modeling (not shown) }\end{array}$ \\
\hline 2. Design & Agreed development scenario & $\begin{array}{l}\text { structurational analysis (interactions), } \\
\text { SSM modeling (not shown), system } \\
\text { definitions }\end{array}$ \\
\cline { 2 - 4 } & Agreed development plan & $\begin{array}{l}\text { structurational analysis } \\
\text { (transformation), SSM modeling (not } \\
\text { shown) }\end{array}$ \\
\hline
\end{tabular}




\subsection{Stage 1}

The analysis of the intranet focused on two areas:

(1) The intranet in use: analysis of the current interactions or social practice involving the intranet.

(2) The intranet in development: analysis of the social practice through which changes to the intranet may currently be effected.

Structurational analysis of the intranet in use is given in Table 2.

The structurational analysis in Table 2 concentrates on the role of the intranet in the current delivery of courses. Although brief, the analysis is significant as it begins to uncover how disenfranchised the students are in the delivery of courses, but also how the design and operation of the intranet reflect very traditional entrenched views of teaching and course management. Built into the structure (context) of departmental social practice was a signification structure in which academic staff take responsibility for getting students through courses,

Table 2. Structurational Analysis of Use System

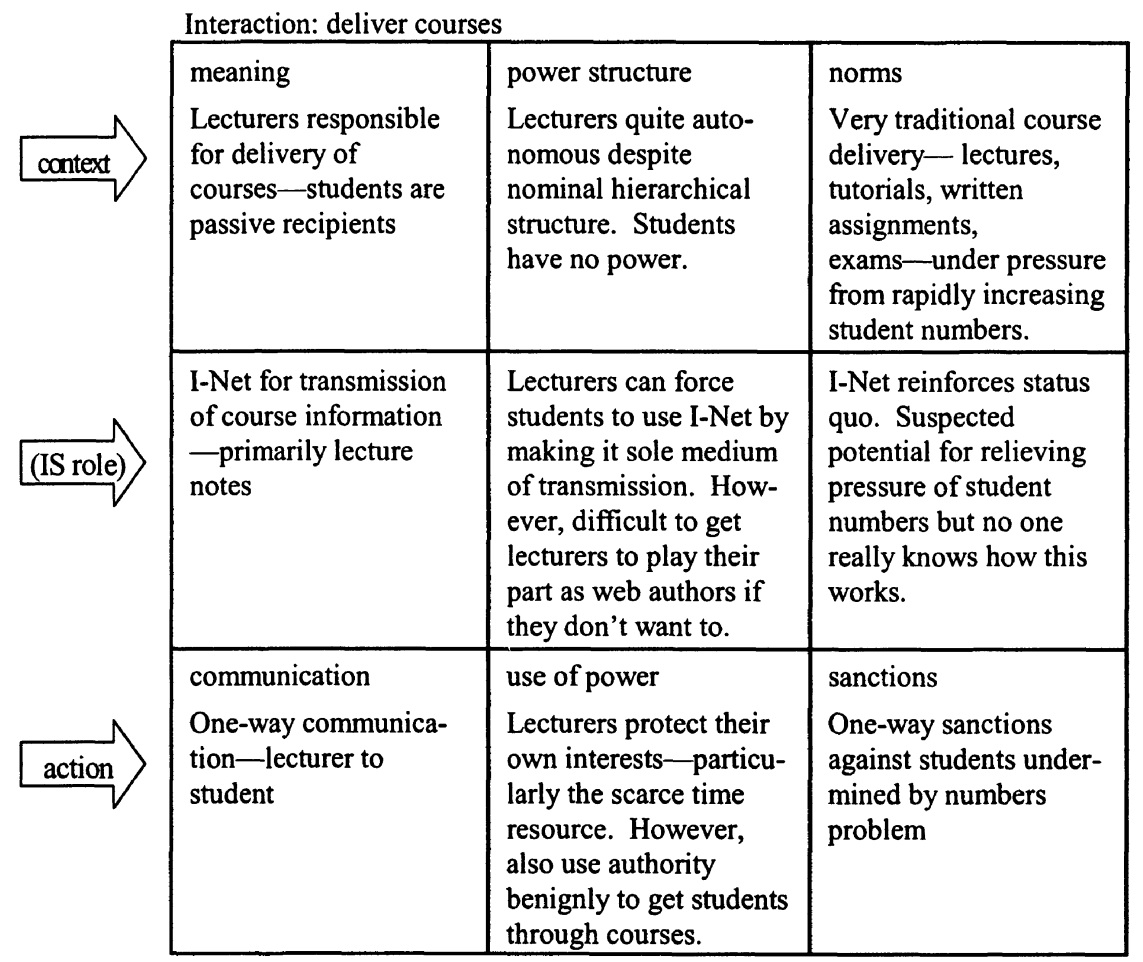


rather than students taking responsibility for their own learning. Two features of the power structure (domination) are evident. The first is the relative autonomy of academic staff, which means that issues to do with intranet development cannot necessarily be solved by managerial edict. The second is the inequality of power between students and academic staff. A rather strongly normative pedagogical method (lectures, tutorials, assignments, exams) was evident throughout the department, but was under pressure from increasing numbers of course and students. When the head of department (DD) abolished tutorials in an attempt to reduce teaching hours (much to the benefit of staff), the vast majority of staff simply pleaded that their course were special cases that could not be run without tutorials, and the normative pedagogical model survived with scarcely a dent. In this environment interactions take a particular form, with the majority of communication unidirectional-from the academic staff, to the student-and with lecturers using the power unbalance to try to protect themselves against increasing workloads. The intranet makes very little impact on this social practice, simply being designed and operated to fit in with and protect the status quo.

Students' comments emphasize the position:

- "The students on the course are using the intranet as a support tool rather than a learning tool. The old-fashioned notice-board is still the first point of contact."

- "Talking about one perspective the intranet does not have students views about the course, all of the pages are dedicated to the staffs background, views, etc.... What viewers would like to see is the student views, why not have a dedicated page to first and final year students on their views of the course and the university. At present there is nothing. Yes there may be a feedback page but does this work? NO!'

- "The intranet is currently organized by courses. While this is a good way to organize it users are used to their accounts being set up in relation to users when they log in. When they access they intranet they may expect the intranet to be structured and organized by user as well."

- "At present, the intranet has not successfully implemented newsgroups, chat forums or any other communication medium that would encourage collaboration or cooperative learning initiatives on-line."

- "If it provides just a simple regurgitation of information that was previously available in paper form-the only purpose it serves is that the responsibility of receiving information has been passed on from the lecturer to the student."

- "Replicates traditional teaching methods."

Although most academic staff members had rather imagined that the intranet would help in the teaching and learning work of the department, and would (in some unspecified way) help deal with the burden of increasing student numbers, 
there was no evidence that this was the case. Its chief function, as the analysis emphasizes, was to distribute information that would previously have been distributed on paper, such as lecture notes and assignments. The most cynical view, expressed by a staff member, was that the intranet was "a system to transfer the cost of printing lecture notes from the department to the students." The intranet was very much built in the image of the department as viewed by the academic staff (pages structured by course and unit, for instance). Since no changes to traditional teaching methods were thought through, it served to reinforce the status quo. Other possible functions were not used much by students. Retrieval time for pages was too slow to permit browsing or searching, which might have encouraged some genuine research activity (for example, trawling for materials on a given topic). Notices were distributed across unit pages without thought to how this might affect the student; for instance, students wanting to find out whether any of their lectures were cancelled in a given week might have to trawl through half a dozen different pages. It remained far easier to look at a conventional notice board.

The study also investigated the development system for the intranet; that is, the mechanisms by which it was built, populated with content and by which changes to it could be effected. Structurational analysis is shown in Table 3.

Interaction analysis is chosen for investigating the development system (even though the nominal aim of a development system is transformation or change) because it represents the current set of practices, the status quo. This analysis represents the current regularity in practice, which is likely to continue unless an effort is made to change it.

In the structure (context) of the social practice that represents the development and management of the intranet, a technical semantic is given rather a high priority. Development is assumed to be a primarily technical activity, and the judgements of more technically literate staff members (such as MS and GM), therefore, have more weight. Nevertheless the technical semantic, and attempts to employ it, can be rather confusing. An e-mail from $\mathrm{GM}$ attempting to expose the "Mozilla munition" (the problem with Netscape Composer that was causing the bad links) had little practical effect, because nobody could understand it. The power (domination) structure of the development system was very fluid and informal (there was no formalized management structure to it). DD, the head of department, acted in a symbolic role as champion, but sometimes undermined his own efforts (for instance, by not bothering to populate his own home pages, which was a small omission that took on some symbolic importance). The web administrator, MF was not an academic member of staff and so had little positional authority. In this context, a dispute between staff (in this case GM and MS) could run for a long time without being resolved. The norm for the management structure was that MF expected to be the implementer of whatever strategy or direction was agreed by the academic staff. Unfortunately this com- 
Table 3. Structurational Analysis of Intranet in Development

Interaction: Intranet development system

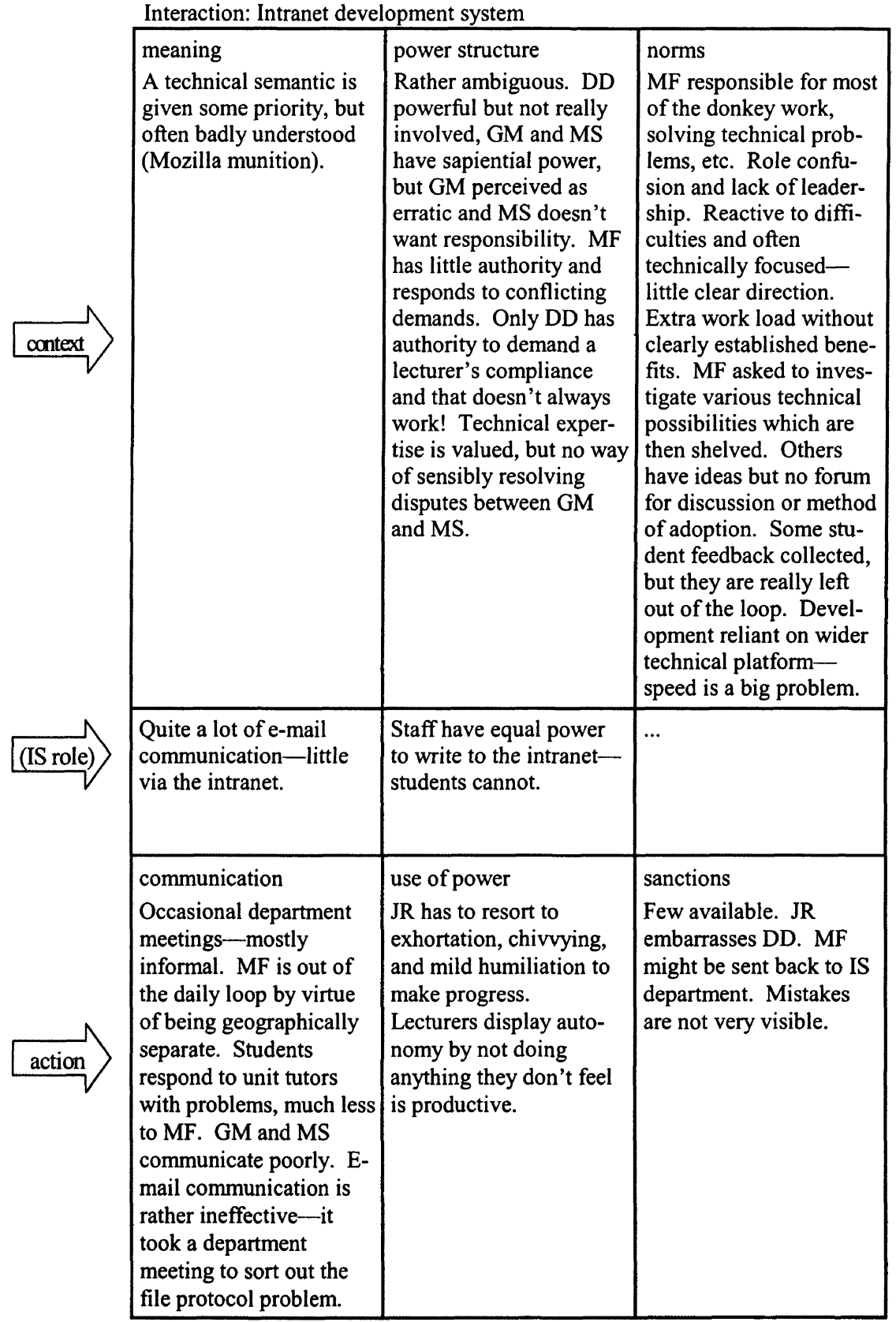


mon sense of purpose was difficult to achieve, and MF was more normally the recipient of many uncoordinated, and sometimes contradictory demands. MF was physically located in a different building, making informal communication rather difficult. In terms of daily interactions, there was much traffic between academic staff and MF, but rather little with students. There was also a rather informal junta of more interested members of the academic staff who debated problems and improvements, and other members of staff might discuss problems or requests with members of the junta. An occasional meeting of the whole department could be marked by violent disagreements - one member of staff walked out of a meeting (an exceptionally rare occurrence). Crucial decisions tended to be taken by the junta and DD. In this situation, achieving the necessary cooperation of academic staff could be quite difficult. One of the researchers (JR), in attempting to get academic staff to populate their home pages, resorted to a rather exhausting mixture of chivvying and bullying, together with a (supposedly) humorous memo devised from DD's homepage (which was more or less blank apart from a very out of date photograph).

In this analysis, some of the difficulties of development are exposed, including the autonomy and varying degrees of interest of the academic staff members, and the kudos associated with technical skills in the development arena. Students are shown to be marginalized in the development process. Students' comments again reinforce the analysis:

- "Some lecturers are not regularly updating their areas on the intranet; therefore, students will have less faith in the benefits of the technology and revert to previous methods of information retrieval."

- "Students have often found that lecture slides cannot be accessed even though they appear to be on-line, and more importantly, they have found that lecture slides and other important materials have not even been published. Many lecturers (authors) either do not bother putting slides on the intranet themselves, or they don't pass them on to the Web Administrator to do it for them. If a virtual department is to be created, and learning capabilities enhanced, this is not a very good way of going about it."

- "Knowledge has to be up to date!! Several pages have information that is completely irrelevant to the students."

- "How could a project team guarantee that the intranet would be used by the students and be functional if it was designed to their requirements, not those of the students?"

- "There does not seem to be any recognition that students want to be empowered and develop themselves and be part of something worthwhile."

- "A lack of stakeholder consultation has resulted in the intranet being perceived as an information tool that stakeholders are forced to comply with." 
- "Due to the lack of consultation, the intranet has had acceptance forced on the majority of the student stakeholders. A real strategy of consultation would prove beneficial to all stakeholders to gain the commitment required. User involvement is a real need to be addressed."

Development of the intranet is quite complex, with many academic staff members authoring their own pages more or less consistently with the given templates. Some staff members were more involved in determining the structure of the pages or mending broken links than others. Lecturers followed the earlyadopters/mainstream-adopters/laggards pattern, which then became reflected in their pages: some rather experimental and heavily programmed at one extreme, some with minimal (textual) content at the other. Because of the pioneering nature of the intranet, there were many issues to be resolved, and a number of disagreements broke out. Management, policy, and team learning become surprisingly important elements in keeping the intranet functional. However, the user community (the students) were left out of the circle, both in the original development effort and in subsequent efforts to change things. This reflected the power orientation of the situation, with the student's interests having little voice. For instance, although a feedback form was included in the design of the intranet, none of the students used it successfully during the first year.

The learning from this analysis was formally recorded in a discussion document called "The Departmental Intranet - One Year On."

\subsection{Stage 2}

The work in stage two involved conceptualization and planning. With the help of the systems and structurational tools, and much discussion with stakeholders, an understanding of what the departmental intranet might be in the future was developed and defined. Scenario building took the form of a workshop with academic staff, administrators and students. A series of potential development routes were discussed (Table 4).

A reasonably accessible form for expressing scenarios was required for workshops and a technique was derived from Mathiassen et al. Information system definitions adapt the SSM root definition to provide a written scenario for a future information system. Several were developed and part of the negotiated outcome is given below.

The new intranet will be.....an information system which is the vehicle for the dissemination of teaching materials, but is also an interactive medium, facilitating dialogues between students and other students as well as students and staff. Examples of such interactions might include discussion groups which support or replace tutorials or provide assignment support, inter- 
Table 4. Potential Development Routes: Departmental Intranet

\begin{tabular}{|l|}
\hline An intranet that supports the needs of part-time students... \\
\hline $\begin{array}{l}\text { An interactive medium that facilitates dialogue between students and students, and students } \\
\text { and staff... }\end{array}$ \\
\hline A virtual office that supports the work of the administrators... \\
\hline A portal to the major IS sites of interest around the globe... \\
\hline An intranet that supports on-line teaching and learning... \\
\hline $\begin{array}{l}\text { A series of topic-based learning zones (knowledge management, system development, } \\
\text { networks)... }\end{array}$ \\
\hline A site that supports the departmental research effort... \\
\hline
\end{tabular}

active teaching materials, online feedback for courses or the intranet, an intranet development forum. It has a common look and feel, particularly at the upper levels, but also some room for experimentation. Pages for part-time students are fully developed, with their particular interests catered for. There are students' pages (a section which is devoted to the students interests, developed and managed by final year students as part of their course work) although these pages go through MF for scrutiny and implementation. There is an (experimental) virtual office which supports the work of the administrative staff, some of whom also develop their own pages. There is a management team with clearly defined roles, and there are also policies and roles that are reasonably well understood by all staff. A majority of academic staff develop and maintain their own pages. There are regular training sessions for page authors. All users report problems and broken links when they meet them. In this way it is intended to give the students more of a voice so that they begin to become investors in the intranet, as well as broadening the base of staff who use it constructively. (Extract from negotiated system definition, internal working paper.)

In this scenario, many of the themes exposed by the earlier analysis were picked up. Issues explicitly addressed include under-involvement of students, focusing the intranet toward a more student-centered view, lack of shared understandings, moving to a more learning-centered environment, differential involvement of staff, and problems in managing the intranet. The availability of solid negotiated understandings of future ambitions for the intranet makes planning for their achievement a great deal easier. The change program envisaged was further supported with structurational analysis (Table 5), this time based on Giddens' dimensions of change model. 
Table 5. Analysis of Proposed Intranet Development Based on Giddons' Dimensions of Change Model

Transformation (change) analysis: Intranet development

\begin{tabular}{|c|c|}
\hline history & direction \\
\hline $\begin{array}{l}\text { The intranet came about through the enthu- } \\
\text { siasm of a small majority of the department. } \\
\text { Some staff rather resented the extra burden of } \\
\text { preparation it represented and remained skep- } \\
\text { tical. In retrospect, the intranet was created in } \\
\text { the image of the department as seen by the } \\
\text { academic staff; its primary use of the techno- } \\
\text { logy is rather basic (distributing previously } \\
\text { printed textual material) and changes to work } \\
\text { practices that might accompany its introduc- } \\
\text { tion were not thought through. Students find } \\
\text { it a little hard to connect with and peripheral } \\
\text { to their needs. However, it has now deve- } \\
\text { loped into an integral, if rather small, part of } \\
\text { the department's work and is obviously here } \\
\text { to stay. }\end{array}$ & $\begin{array}{l}\text { The intranet should change in the direction of } \\
\text { - greater focus on the needs and views of } \\
\text { students } \\
\text { - more interactivity } \\
\text { - greater clarity in management roles } \\
\text { - wider acceptance by staff and students alike } \\
\text { - more genuine interactive teaching and } \\
\text { learning } \\
\text { - an additional focus on administrative tasks } \\
\text { - better organization of materials, perhaps } \\
\text { with different views for users or groups of } \\
\text { users } \\
\text { - better ways of searching for materials } \\
\text { Most of these changes are dependent on } \\
\text { improvements in the technical infrastructure } \\
\text { and updating technical knowledge and skills. } \\
\text { There are strong social (training, developing } \\
\text { shared understandings) and political } \\
\text { (influencing the faculty infrastructure devel- } \\
\text { opment) elements. }\end{array}$ \\
\hline degree & speed \\
\hline $\begin{array}{l}\text { The change should probably be quite marked } \\
\text { because of the possibilities the technology } \\
\text { holds for offsetting the burden of higher num- } \\
\text { bers. However, this is almost certainly } \\
\text { beyond the grasp of the department because } \\
\text { of the radical thinking, changes to established } \\
\text { work practices, and investment required. } \\
\text { These factors create too much risk for the } \\
\text { consensual nature of decision making to } \\
\text { grapple with. }\end{array}$ & $\begin{array}{l}\text { Development is rather paralyzed at present. } \\
\text { The factors are autonomy of lecturers (which } \\
\text { makes it hard to create consensus) and burden } \\
\text { of increasing numbers (which creates serious } \\
\text { pressures on time)-the two combining to } \\
\text { slow down decision making. Many changes } \\
\text { are dependent on cooperation of lecturers, so } \\
\text { development will be slow. This, paradox- } \\
\text { ically, creates more risks than it avoids } \\
\text { because of the speed of development of the } \\
\text { technology. }\end{array}$ \\
\hline
\end{tabular}

The understandings gained through analysis, scenario development, and change planning were developed into an action plan. The direction of change is based on the collaborative scenario work and addresses many of the issues raised in the earlier structurational analysis. The degree and speed of change will be relatively small, because of the rather complex set of development difficulties exposed in the earlier analysis. 
The proposals were discussed at a planning meeting (junta and DD), adopted with some changes and are presently being implemented. Progress to date includes:

- Acquisition and dissemination of a new authoring tool (to replace the problematic Netscape Composer and allow standardization of pages)

- Planning for training on the new tool

- Appointment of a formal overseer of the intranet (to formalize management responsibilities)

- Acquisition of a Windows NT intranet server (to facilitate active server pages in order to develop student focused intranet views)

- Acquisition of a tool to manage the interface between databases and web pages (see previous point)

- Development of prototype for alerting the students to personally relevant new pages (combining database and HTML technologies)

- Planning for inclusion of student home pages as part of induction exercises (as a start in including the student voice)

- Planning for the virtual office

The intervention should be seen as part of an evolving change to working practices and the intranet, rather than the whole development picture. Even three months later, many of the issues have changed substantially. The status of the project within the department's workload was surprisingly low, considering the academic focus of the department (business information technology). Information systems are generally seen as more important in other people's work than our own. The intervention deliberately focused on the social elements rather than technical details, but these were naturally also important. For instance, a suggestion to redirect the intranet toward the students' concerns by linking it to the database holding student marks was dropped because the technical security issues could not be resolved. Interestingly, technical rationality was sometimes used in a legitimizing role. Participants with better technical knowledge had better credibility in the political decision making process simply because development was viewed as a predominantly technical arena. The account presented in this paper is over-rational in one sense: it reinforces the view that rational analysis leads to rational change. In fact it was the negotiation process together with changes to the actors' interpretive and signification schemes that were the most important factors in the intervention, with the rational analysis playing a significant facilitating role for those changes.

\section{CONCLUSIONS}

This paper outlined an intranet development project that used an action research framework heavily dependent on structuration theory. The principal 
insight gained was that the academic staff had created the intranet according to their own perception of the department's activities, without valuing students' perceptions. This is a common fault of systems developers, but it is not an easy understanding to acquire in this situation because of the challenge to entrenched mental models, and it is a difficult position to change, because of the challenge to powerful stakeholders' interests. Other insights followed in a complex pattern. We do not think that these insights would be available to systems developers working with conventional tools such as data-flow diagrams or object models. These insights helped in the conceptualization of an improved set of interactions (information practice) focused around a more student-centered intranet. The structurational tools were also useful in this conceptualization. The final role of the tools was to help plan an organized change that would help achieve the desired set of interactions. The communicative value of the analysis is important here, because rational analysis changes nothing without the active involvement and commitment of participants. A measure of the success of the project is that many of the planned improvements have already been achieved, some three months after the adoption meeting.

The significance of this work is twofold. First, it serves as an (admittedly imperfect) model for the use of analysis informed by social theory in development work, putting to practical use a body of theory (structuration theory in IS) that has largely remained the preserve of academics. In principle, any social theory could be adapted for the same purpose. Second, it serves, because it is founded on social theory, to challenge many of the stereotypical assumptions of the information system development community (assumptions that are not always shared by IFIP WG8.2 members). The focus of the work is not technical, but social, and it is not dominated by software development considerations (in this case these are incidental). Organizational problems are the focus of the work, rather than being trivialized to the status of requirements. Those organizational problems are taken to be socially constructed and evolving, rather than given and static; requirements gathering is, therefore, dispensed with in favor of negotiating better practices and information provision. Computing systems are never considered in isolation from their social context and those social contexts are assumed to be constructed, negotiated, and evolving, not objective external environments.

\section{REFERENCES}

Avison, D. E., and Wood-Harper, A. T. Multiview: An Exploration in Information Systems Development, Maidenhead, England: McGraw-Hill, 1990.

Barley, S. R. "The Alignment of Technology and Structure Through Roles and Networks," Administrative Science Quarterly (35), 1990, pp. 61-103.

Barley, S. R. "Technology as an Occasion for Structuring: Evidence from Observation of CT Scanners," Administrative Science Quarterly (31), 1986, pp. 78-108. 
Baskerville, R. "Semantic Database Prototypes," Journal of Information Systems (3:2), 1993, pp. 119-144.

Baskerville, R., and Wood-Harper, A. T. "Diversity in Information Systems Action Research Methods," European Journal of Information Systems (7), 1998, pp. 90-107.

Brooks, L. "Structuration Theory and New Technology: Analyzing Organizationally Situated Computer-Aided Design," Information Systems Journal (7), 1997, pp. 133-151.

Checkland, P. B. "From Framework Through Experience to Learning: The Essential Nature of Action Research," in Information Systems Research: Contemporary Approaches and Emergent Traditions, H-E. Nissen, H. K. Klein, and R. A. Hirschheim (eds), Amsterdam: NorthHolland, 1991, pp. 397-403.

Checkland, P. B., and Holwell, S. Information, Systems, and Information Systems, Chichester, England: Wiley, 1998.

Checkland, P. B., and Scholes, J. SSM in Action, Chichester, England: John Wiley, 1990.

Coad, P., and Yourdon, E. Object Oriented Analysis (also Object Oriented Design), New York: Yourdon Press, 1990.

DeSanctis, G., and Poole, M. S. "Capturing the Complexity in Advanced Technology Use: Adaptive Structuration Theory," Organization Science (5:2), 1994, pp. 121-147.

Giddens, A. The Constitution of Society, Cambridge, MA: Polity Press, 1984.

Hammer, M., and Champey, J. Re-engineering the Corporation: A Manifesto for Business Revolution, New York: Harper Collins, 1993.

Hult, M., and Lenning, S-A. "Towards a Definition of Action Research," Journal of Management Studies (17), May 1980, pp. 241-250.

Jepsen, L., Mathiassen, L., and Nielsen, P. "Back to the Thinking Mode: Diaries for the Management of Information Systems Development Projects," Behaviour and Information Technology (8:3), 1989, pp. 207-217.

Jones, M. "Structuration and IS," in Re-Thinking Management Information Systems, W. L. Currie and R. D. Galliers (edsl), Oxford: Oxford University Press, 1997.

Jones, M., and Nandhakumar, J. "Structured Development? A Structurational Analysis of the Development of an Executive Information System," in Human, Organizational and Social Dimensions of Information System Development, D . E. Avison, J. E. Kendall, and J. I. DeGross (eds.), Amsterdam: North-Holland, 1993.

Karsten, H. "It's Like Everyone Working Round the Same Desk: Organizational Readings of Notes," Scandinavian Journal of Information Systems (7:1), 1995, pp. 7-34.

Kyng, M. "Designing for Cooperation," Communications of the ACM (34:12), 1991, pp. 65-73.

Mathiassen, L., Munk-Madsen, A., Nielsen, P., and Stage, J. Object-Oriented Analysis and Design, Aalborg, Denmark: Marko Publishing ApS, 2000.

Mumford, E. Designing Human Systems for New Technology: The ETHICS Method, Manchester: Manchester Business School, 1983.

Nagasundram, M., and Bostrom, R. P. "The Structuring of Creative Processes Using GSS: A Framework for Research," Journal of Management Information Systems (11:3), 1994, pp. 87114.

Naur, P. "Program Development Studies Based on Diaries," in Psychology of Computer Use, T. Green, S. Payne, and G. van der Veer (eds.), London: Academic Press, 1983.

Orlikowski, W. J. "The Duality of Technology: Rethinking the Concept of Technology in Organizations," Organization Science (3:3), 1992, pp. 398-429.

Orlikowski, W. J., and Robey, D. "IT and the Structuring of Organizations," Information Systems Research (2:2), 1991, pp. 143-169.

Rapoport, R. N. "Three Dilemmas of Action Research," Human Relations (23), 1970, pp. 499513.

Reponen, T. "Action Research in Information Systems Strategy: Formulation and Implementation," in Action Research in Management Information Systems Studies, L. von Hellens (ed.), Turku, Finland: Turku School of Economics, 1992. 
Rose, J. "Evaluating the Contribution of Structuration Theory to the Information Systems Discipline,"in Proceedings of the Sixth European Conference on Information Systems, W. E. J. Baets (ed.), Aix-en-Provence, France, 1998, pp. 910-924.

Rose, J. Information Systems Development as Action Research: Soft Systems Methodology and Structuration Theory, Unpublished Ph.D. Thesis, Lancaster University, 2000.

Rose, J. "Soft Systems Methodology as a Social Science Research Tool," Systems Research and Behavioural Science (14), 1997, pp. 249-258.

Rose, J. "Towards a Structurational Theory of IS, Theory Development and Case Study Illustrations," in Proceedings of the Seventh European Conference on Information Systems, J. Pries-Heje, C. Ciborra, K. Kautz, J. Valor, E. Christiaanse, D. Avison, and C. Heje (eds.), Copenhagen, Denmark, 1999, pp. 640-655.

Susman, G. I., and Evered, R. D. "An Assessment of the Scientific Merits of Action Research, Administrative Science Quarterly (23), 1978, pp. 582-603.

Walsham, G. Interpreting Information Systems, Chichester, England: Wiley, 1993.

Walsham, G., and Han, C. K. "Structuration Theory and Information Systems Research," Journal of Applied Systems Analysis (17), 1991, pp. 77-85.

Yates, J., and Orlikowski, W. J. "Genres of Organizational Communication: A Structurational Approach to Studying Communication and Media," Academy of Management Review (17:2), 1992, pp. 299-326.

\section{About the Authors}

Jeremy Rose won an exhibition to read English at Cambridge and subsequently trained to be a musician at the Royal College of Music in London. After working for some years for the Rambert Dance Company and Music Projects London, his career was cut short by injury and he retrained at Lancaster, gaining his M.Sc. in Information Management with distinction. As a senior lecturer in Business Information Technology in the Faculty of Management and Business at the Manchester Metropolitan University, he continued to collaborate with Peter Checkland on research projects. He is also visiting associate professor in the Department of Computing Science at the University of Aalborg. While completing his $\mathrm{Ph}$.D. at Lancaster, he has published in management, systems, and IS forums. His research interests include IS development and evaluation, systems methodology, structuration theory and actor network theory, BPR and knowledge management, the health service and inter/intranet development. Jeremy can be reached by e-mail at jeremy@cs.auc.dk.

Paul Dunning-Lewis originally graduated in Computer Science and worked as an analyst programmer with oil companies before obtaining his Master's and Doctorate in Systems. He entered academic life only after some time in consultancy work and a further period in the oil industry, where he worked for several years as a database designer. After lecturing in systems analysis at City University he moved to the Management School at Lancaster in 1986. This background is reflected in his research interests which center around the use of soft systems methodology in the development of information systems, and in the 
development of interpretative approaches to the design of data storage mechanisms. He is the author of numerous academic papers and of the widely used text Information Systems Development: Systems Thinking in the Field of Information Systems (Pitman 1994). Paul can be reached by e-mail at p.lewis@lancaster.ac.uk. 